\title{
Astragalus polysaccharide induces anti-inflammatory effects dependent on AMPK activity in palmitate-treated RAW264.7 cells
}

\author{
JINZHI LU, XIONG CHEN, YINGYING ZHANG, JIAN XU, LIANGLU ZHANG, ZHI LI, \\ WANHONG LIU, JINGPING OUYANG, SONG HAN and XIAOHUA HE \\ School of Basic Medical Sciences, Wuhan University, Wuhan 430071, P.R. China \\ Received January 14, 2013; Accepted March 11, 2013
}

DOI: $10.3892 /$ ijmm.2013.1335

\begin{abstract}
Astragalus polysaccharide (APS) has been reported to increase insulin sensitization and to ameliorate diabetes in animal models, and studies have demonstrated that this effect may be correlated with its anti-inflammatory roles in vivo and in vitro. However, the potential pharmacological mechanisms of APS in anti-inflammatory regulation are still poorly understood. Herein, RAW264.7 cells treated with APS showed anti-inflammatory effects. Interleukin (IL)-10 protein levels and expression of most of the anti-inflammatory genes, including IL-10, macrophage mannose receptor (MMR), arginase, Dectin-1, YM-1 and YM-2, were significantly increased after treatment with APS for $24 \mathrm{~h}$. Furthermore, to determine whether APS plays a potential role in RAW264.7 cell inflammation, we pretreated RAW264.7 cells with APS in the presence of palmitate. The results showed that APS markedly recovered the impairment of AMPK activity induced by palmitate. Furthermore, APS induced IL-10 protein production and anti-inflammatory gene expression of IL-10, MMR, Dectin-1, arginase, YM-1 and YM-2. Additionally, APS inhibited IL-1 $\beta$ protein production and expression of most of the pro-inflammatory genes, such as IL-1 $\beta$, iNOS, MCP-1, IL-6 and CD11c but not tumor necrosis factor (TNF)- $\alpha$. Notably, the effect of APS on inflammatory genes, except for TNF- $\alpha$, was abrogated when AMPK activity was inhibited using a DN-AMPK plasmid. These results suggest that APS effectively ameliorates palmitate-induced pro-inflammatory responses through AMPK activity.
\end{abstract}

Correspondence to: Dr Song Han or Professor Xiaohua He, School of Basic Medical Sciences, Wuhan University, Wuhan 430071, P.R. China

E-mail: hansong@whu.edu.cn

E-mail: hexiaohua@whu.edu.cn

Key words: Astragalus polysaccharide, AMPK, RAW264.7, inflammation, diabetes

\section{Introduction}

Chronic low-grade inflammation plays an important role in the development of metabolic disorders such as insulin resistance and diabetes mellitus $(1,2)$. High levels of saturated fatty acids are among the main culprits in these metabolic disorders (3). Palmitate is a type of saturated free fatty acid that stimulates macrophages to express high levels of pro-inflammatory cytokines such as tumor necrosis factor (TNF)- $\alpha$, interleukin (IL)- 6 and IL-1 $\beta$. These unique properties are reported to be the cause of insulin resistance $(2,4,5)$. Inhibition of pro-inflammatory cytokines is reported to recover the anti-inflammatory phenotype, improve insulin resistance and alleviate metabolic disorders $(5,6)$. These observations suggest that regulation of macrophage inflammation induced by palmitate may be an important therapeutic target for treating metabolic disorders.

The Astragalus polysaccharide (APS) is widely used as an antimicrobial agent and an immune stimulator in developing countries (7). Recent studies have shown that APS has insulinsensitizing, hypoglycemic effects $(8,9)$. Research demonstrated that APS increases the expression of anti-inflammatory cytokines including IL-10 and transforming growth factor (TGF) $-\beta$ in diabetic mice. The authors also demonstrated that APS ameliorates diabetes, which may suggest that APS has anti-inflammatory effects $(10,11)$. Furthermore, in our previous study we found that APS increased AMPK activity in skeletal muscle (12). A previous study demonstrated that AMPK is involved in regulating inflammatory responses (13). These results suggest that APS may play anti-inflammatory roles in vivo and in vitro. Furthermore, studies have demonstrated that APS exerted anti-inflammatory effects against lipopolysaccharide (LPS)-induced inflammation in several cell lines $(14,15)$. However, APS was found to stimulate the expression of TNF- $\alpha$ and iNOS to exert pro-inflammatory effects in the murine macrophage RAW264.7 cell line $(16,17)$. The RAW264.7 cell line is widely used to study inflammatory responses associated with metabolic disorders (4-6). However, the pro-inflammatory effects of APS in RAW264.7 cells conflict with its beneficial effects in reducing insulin resistance in metabolic disorders. Questions still remain whether APS plays an anti-inflammatory or pro-inflammatory role in RAW264.7 cells and how APS affects macrophage cells. 
In the present study, we demonstrated that APS affects inflammatory responses in murine macrophage RAW264.7 cells with or without palmitate treatment. APS stimulated RAW264.7 cells to produce IL-10 protein and express most of the anti-inflammatory genes. Additionally, APS induced recovery of IL-10 protein, the expression of a number of antiinflammatory genes and inhibited IL- $1 \beta$ protein production, as well as several pro-inflammatory genes, in the presence of palmitate in RAW264.7 cells. These anti-inflammatory effects of APS in palmitate-induced RAW264.7 cells were abrogated by inhibiting AMPK activity. Taken together, our results revealed that Astragalus polysaccharide evoked antiinflammatory effects that were dependent on AMPK activity in palmitate-induced RAW264.7 cells.

\section{Materials and methods}

Preparation of APS extracts. Astragalus membranaceus (Fisch.) Bunge var. mongholicus (Bunge) Hsiao was purchased from Shanghai Medicinal Materials Co. (Shanghai, China). We extracted the main bioactive component, Astragalus polysaccharide (APS), with optimized techniques using direct water decoction according to a previously described procedure with some modifications (18). In brief, APS, a hazel-colored and water-soluble powder, was diluted in DMEM (SH30022.1B; HyClone) to a working concentration of $10 \%$. This solution was filtered three times with a $0.22-\mu \mathrm{m}$ filter before use. All APS dilutions were limited to a one-time use. The extract was identified by the Department of Authentication of Chinese Medicine, Hubei College of Chinese Traditional Medicine (Wuhan, China). The endotoxin contaminants in the APS working solution was tested and limited to $<0.05 \mathrm{EU} / \mathrm{ml}$.

Preparation of palmitate. BSA-bound palmitate was constructed according to a previously described procedure with some modifications (19). In brief, palmitate was dissolved in ethanol to a concentration of $0.75 \mathrm{M}$, and then diluted with $20 \%$ FFA-free BSA to a working concentration of $7.5 \mathrm{mM}$ (the molar ratio of palmitate to BSA was 2.5 ). This stock solution was filtered and stored at $-20^{\circ} \mathrm{C}$ to be used within two weeks. The same concentration of ethanol mixed with $20 \%$ of BSA was used as a control. The endotoxin contaminants in the palmitate working solution was tested and limited to $<0.3 \mathrm{EU} /$ $\mathrm{ml}$. This amount of contaminating endotoxin was previously proven not to be sufficient to activate RAW264.7 cells (5).

Cell culture. The murine macrophage cell line RAW264.7 was purchased from the Shanghai Cellular Research Institute (China) and cultured in DMEM supplemented with $10 \%$ fetal bovine serum (SV30087; HyClone), $100 \mathrm{U} / \mathrm{ml}$ penicillin and $100 \mu \mathrm{g} / \mathrm{ml}$ streptomycin at $37^{\circ} \mathrm{C}$ in a humidified atmosphere of $5 \% \mathrm{CO}_{2}$. The cells were trypsinized at $80 \%$ confluence with $0.25 \%$ trypsin/0.02\% EDTA in Hank's solution for 1-3 min and resuspended in a complete culture medium. These culture materials were all endotoxin-free.

Western blotting and antibody reagent. The cells in 6-well plates $\left(1 \times 10^{6}\right.$ cells/plate) were lysed in cold buffer containing 50 mM HEPES, pH 7.4, 150 mM NaCl, 200 mM NaF, 20 mM sodium pyrophosphate, $10 \%$ glycerol, $1 \%$ Triton X-100, $4 \mathrm{mM}$
Table I. Primer sequences used in this study.

\begin{tabular}{|c|c|}
\hline Gene & Primer sequences $\left(5^{\prime}-3^{\prime}\right)$ \\
\hline \multicolumn{2}{|l|}{$\beta$-actin } \\
\hline Sense & TCA CCC ACA CTG TGC CCA TCT ACG A \\
\hline Antisense & GGA TGC CAC AGG ATT CCA TAC CCA \\
\hline \multicolumn{2}{|l|}{ IL-10 } \\
\hline Sense & AGA AGC ATG GCC CAG AAA TC \\
\hline Antisense & CCA AGG AGT TGT TTC CGT TAGC \\
\hline \multicolumn{2}{|c|}{ Mannose receptor } \\
\hline Sense & ATG CCA AGT GGG AAA ATC TG \\
\hline Antisense & TGT AGC AGT GGC CTG CAT AG \\
\hline \multicolumn{2}{|l|}{ Dectin-1 } \\
\hline Sense & CAT CGT CTC ACC GTA TTA ATG CAT \\
\hline Antisense & CCC AGA ACC ATG GCC CTT \\
\hline \multicolumn{2}{|l|}{ YM-1 } \\
\hline Sense & AAT GAT TCC TGC TCC TGT GG \\
\hline Antisense & ACT TTG ATG GCC TCA ACC TG \\
\hline \multicolumn{2}{|l|}{ YM-2 } \\
\hline Sense & CAC GGC ACC TCC TAA ATT GT \\
\hline Antisense & GCT GGA CCA CCA GGA AAG TA \\
\hline \multicolumn{2}{|l|}{ TNF- $\alpha$} \\
\hline Sense & AAA ATT CGA GTG ACA AGC CTG TAG \\
\hline Antisense & CCC TTG AAG AGA ACC TGG GAG TAG \\
\hline \multicolumn{2}{|l|}{ IL-1 $\beta$} \\
\hline Sense & GAT CCA CAC TCT CCA GCT GCA \\
\hline Antisense & CAA CCA ACA AGT GAT ATT CTC CAT G \\
\hline \multicolumn{2}{|l|}{ IL-6 } \\
\hline Sense & AAG TGC ATC ATC GTT GTT CAT ACA \\
\hline Antisense & GAG GAT ACC ACT CCC AAC AGA CC \\
\hline \multicolumn{2}{|l|}{ CD11c } \\
\hline Sense & ACA CAG TGT GCT CCA GTA TGA \\
\hline Antisense & GCC CAG GGA TAT GTT CAC AGC \\
\hline \multicolumn{2}{|l|}{ iNOS } \\
\hline Sense & CAG CTG GGC TGT ACA AAC CTT \\
\hline Antisense & CAT TGG AAG TGA AGC GTT TCG \\
\hline \multicolumn{2}{|l|}{ Arginase } \\
\hline Sense & AGA GCT GAC AGC AAC CCT GT \\
\hline Antisense & GGA TCC AGA AGG TGA TGG AA \\
\hline \multicolumn{2}{|l|}{ MCP-1 } \\
\hline Sense & TCT GGG CCT GCT GTT CAC A \\
\hline Antisense & CCT ACT CAT TGG GAT CAT CTT GCT \\
\hline
\end{tabular}

TNF- $\alpha$, tumor necrosis factor- $\alpha$; IL-1 $\beta$, interleukin-1 $\beta$; MCP-1, monocyte chemoattractant protein-1.

sodium orthovanadate, $2 \mathrm{mM}$ phenylmethylsulfonyl fluoride and $1 \mathrm{mM}$ EDTA. Whole cell lysates $(20 \mu \mathrm{g})$ were resolved by SDS-PAGE and transferred onto polyvinylidene difluoride membranes (Immobilon-P; Millipore, Bedford, MA, USA). Following blocking with 5\% milk in TBST, the membranes were probed with primary antibodies as indicated and subsequently incubated with horseradish peroxidase-conjugated secondary antibodies for visualization with enhanced chemiluminescence (Thermo Scientific, USA). The blots were stripped in western blotting stripping buffer containing 2\% SDS, $62.5 \mathrm{mM}$ Tris- $\mathrm{HCl}(\mathrm{pH} 6.8)$ and $100 \mathrm{mM} \beta$-mercaptoethanol. 
A

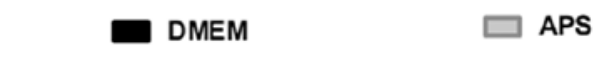

IL-10

MMR

Arginase Dectin-1

YM-1

YM-2
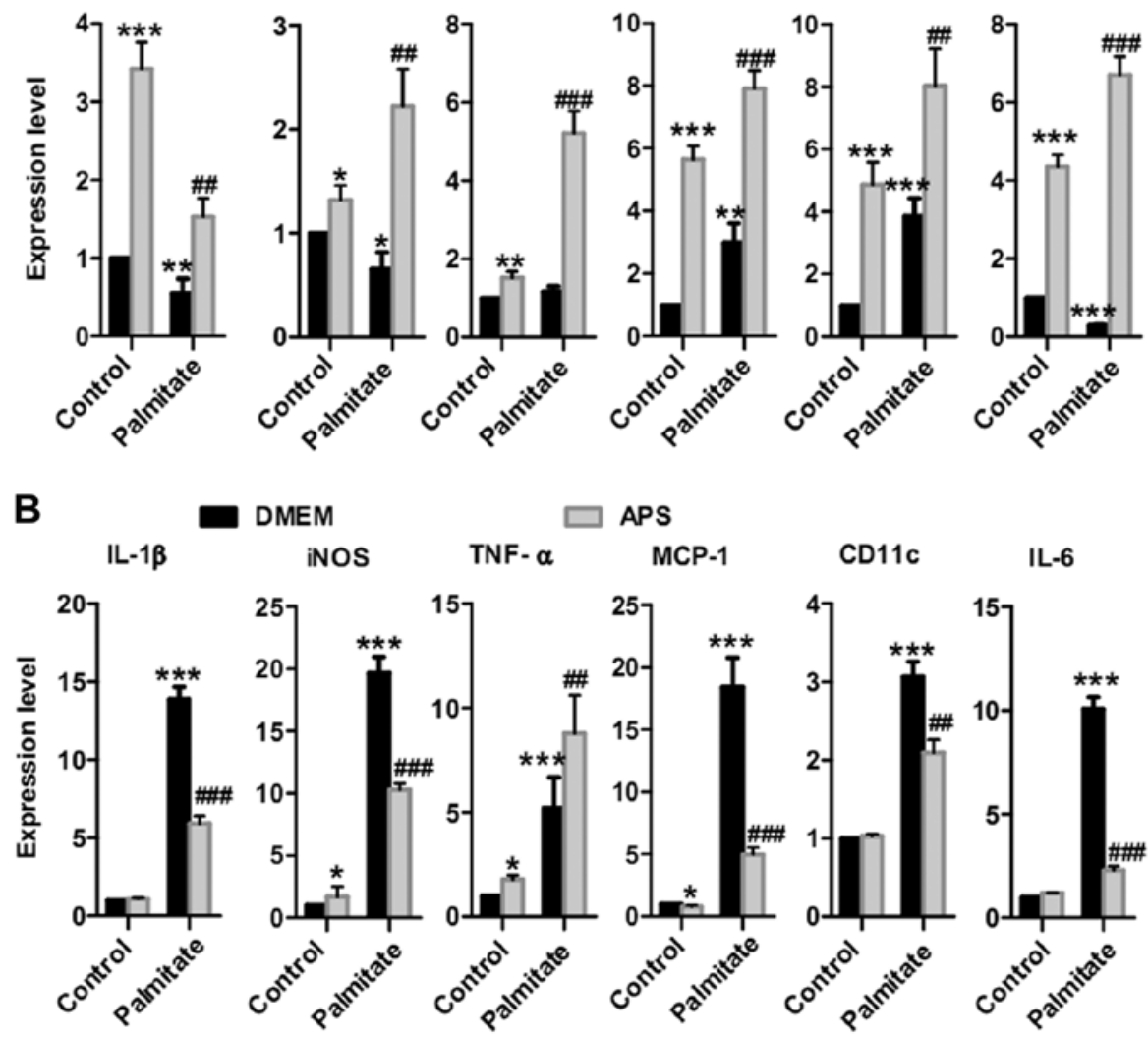

Figure 1. APS modulates the expression of inflammatory genes in RAW264.7 cells with or without palmitate treatment. RAW264.7 cells were pretreated with $(400 \mu \mathrm{g} / \mathrm{ml})$ or without APS for $24 \mathrm{~h}$; the culture medium was removed, and the cells were cultured again with palmitate $(0.5 \mathrm{mM})$ for $12 \mathrm{~h}$. Cells without palmitate treatment were designated as the control groups. (A) Anti-inflammatory gene expression levels were analyzed using real-time PCR. (B) Pro-inflammatory gene expression levels were analyzed at the same time. Data shown are the means \pm SD of triplicate determinations and represent 3 independent experiments with similar results. ${ }^{*} \mathrm{P}<0.05,{ }^{* *} \mathrm{P}<0.01$ and ${ }^{* * *} \mathrm{P}<0.001$ compared with the control group; ${ }^{\#} \mathrm{P}<0.05,{ }^{\# \#} \mathrm{P}<0.01$ and ${ }^{\# \# \#} \mathrm{P}<0.001$ compared with the palmitate group.

Phosphorylated-AMPK (Thr172) and AMPK antibodies were purchased from Cell Signaling Technology (Beverly, MA, USA). Phospho-AMPK and the total AMPK levels were assayed by densitometry with Quantity One 4.4 software.

Reverse transcription and real-time PCR. Total RNA obtained from murine RAW264.7 macrophages in 6-well plates $\left(1 \times 10^{6}\right.$ cells/plate) was prepared with RNeasy ${ }^{\circledR}$ Mini kit columns (Qiagen) using the manufacturer's protocol. cDNA synthesis was performed with $1 \mu \mathrm{g}$ of total RNA using hexamers for priming and the QuantiTect ${ }^{\circledR}$ Reverse Transcription kit (Qiagen) according to the manufacturer's recommendations. Quantitative real-time PCR was performed on a LightCycler system (Bio-Rad iQ-2; Bio-Rad) using QuantiFast $^{\mathrm{TM}}$ SYBR $^{\circledR}$-Green PCR (Genocopy). Ten microliters of reaction mixture was incubated, and amplification was performed for 50 cycles $\left(30 \mathrm{sec}\right.$ at $95^{\circ} \mathrm{C}$ and $30 \mathrm{sec}$ at $60^{\circ} \mathrm{C}$ ). The primers (at a final concentration of $10 \mathrm{mM}$ ) were designed with the Primer 5 software (Table I). The $\beta$-actin mRNA level was used as the internal control. All samples were run in triplicates. The qRT-PCR results were analyzed as previously described (20).

IL-10 and IL-1 $\beta$ ELISA assays. The RAW264.7 cells in 6 -well plates $\left(1 \times 10^{6}\right.$ cells/plate $)$ were incubated with APS.
Supernatants were recovered and frozen at $-80^{\circ} \mathrm{C}$ before analysis. The production of IL-10 and IL-1 $\beta$ in cell supernatants was determined with an ELISA kit (R\&D Systems, USA) according to the manufacturer's instructions.

DN-AMPK and pcDNA-Zeo plasmid transfection. DN-AMPK $\alpha 1$ (dominant negative) and the control vector, pcDNA-Zeo, were gifts from Professor Carling Dave (Imperial College, London, UK). The plasmids were transfected into RAW264.7 cells using Lipofectamine ${ }^{\mathrm{TM}} 2000$ (Invitrogen) according to the manufacturer's protocol. All plasmids used here were removed from endotoxin, and the amount of contaminating lipopolysaccharide was tested to be $<0.01 \mathrm{EU} / \mathrm{ml}$.

Statistical analysis. Data are expressed as the means \pm standard deviation (SD). Data were analyzed with SPSS 17.0 software and tested by one-way analysis of variance (ANOVA). $\mathrm{P}<0.05$ was defined as indicating a statistically significant result.

\section{Results}

APS modulates the expression of inflammatory genes in RAW264.7 cells. To ascertain whether APS modulates macrophage inflammatory responses with or without palmitate, IL-10, macrophage mannose receptor (MMR), arginase, 
A

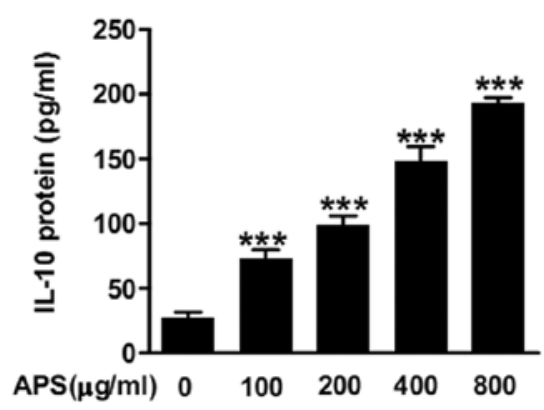

B

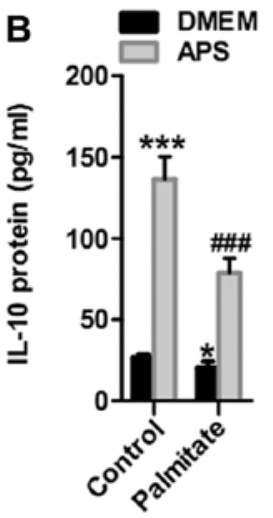

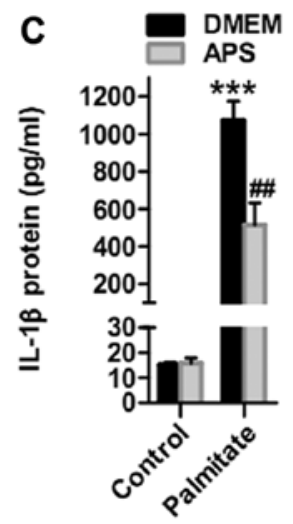

Figure 2. APS enhances IL-10 and suppresses IL-1 1 protein secretion in RAW264.7 cells. (A) IL-10 protein was quantitatively analyzed in RAW264.7 cells treated with escalating concentrations of APS $(0-800 \mu \mathrm{g} / \mathrm{ml})$ for $24 \mathrm{~h}$. (B and C) RAW264.7 cells were pretreated with (400 $\mu \mathrm{g} / \mathrm{ml})$ or without APS for $24 \mathrm{~h}$; the culture medium was removed and the cells were cultured again with palmitate $(0.5 \mathrm{mM})$ for $12 \mathrm{~h}$. Cells without palmitate treatment were designated as the control groups. IL-10 and IL-1 $\beta$ protein levels were analyzed. Data shown are the means \pm SD of triplicate determinations and represent independent experiments with similar results. ${ }^{*} \mathrm{P}<0.05,{ }^{* *} \mathrm{P}<0.01$ and ${ }^{* * *} \mathrm{P}<0.001$ compared with the control group; ${ }^{\# \#} \mathrm{P}<0.01$ and ${ }^{\# \# \#} \mathrm{P}<0.001$ compared with the palmitate group.

A

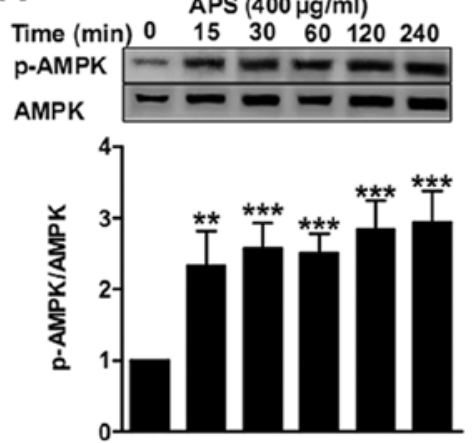

B

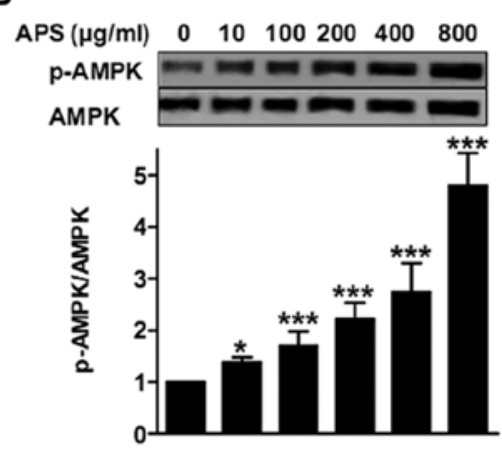

C

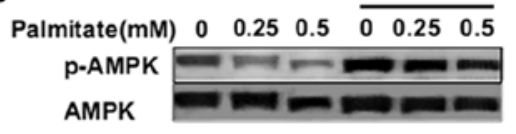

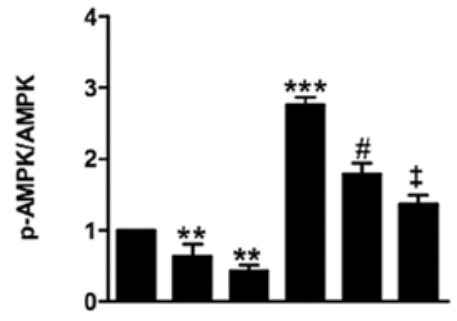

Figure 3. APS recovers the impaired AMPK activity induced by palmitate in RAW264.7 cells. RAW264.7 cells were treated with (A) $400 \mu \mathrm{g} / \mathrm{ml}$ APS for the indicated time periods or with (B) increasing APS concentrations $(0-800 \mu \mathrm{g} / \mathrm{ml})$ for $3 \mathrm{~h}$. (C) RAW264.7 cells were pretreated with (400 $\mu \mathrm{g} / \mathrm{ml})$ or without APS for $3 \mathrm{~h}$ and then cultured with palmitate for $2 \mathrm{~h}$. The total AMPK and activity of AMPK at the site of Thr172 were analyzed by western blotting. Data shown are the means $\pm \mathrm{SD}$ of triplicate determinations and represent 3 independent experiments with similar results. ${ }^{*} \mathrm{P}<0.05,{ }^{* *} \mathrm{P}<0.01$ and ${ }^{* * * *} \mathrm{P}<0.001$ compared with the control group; ${ }^{*} \mathrm{P}<0.05$ compared with the palmitate $(0.25 \mathrm{mM})$ group; ${ }^{*} \mathrm{P}<0.01$ compared with the palmitate $(0.5 \mathrm{mM})$ group.

Dectin-1, YM-1 and YM-2 were analyzed as anti-inflammatory genes. Conversely, IL-1 $\beta$, iNOS, TNF- $\alpha$, monocyte chemoattractant protein-1 (MCP-1), CD11c and IL-6 were analyzed as pro-inflammatory genes $(20,21)$. APS stimulated anti-inflammatory gene expression in the RAW264.7 cells: $3.4 \pm 0.3$-fold increase in IL-10, 1.3 \pm 0.1 -fold increase in MMR, 1.5 \pm 0.2 fold increase in arginase, 5.6 \pm 0.4 -fold increase in Dectin-1, $4.9 \pm 0.6$-fold increase in YM-1 and 4.4 \pm 0.3 -fold increase in YM-2 (Fig. 1A). APS also recovered the expression of most of the anti-inflammatory genes in the palmitate-treated groups: 2.8 \pm 0.4 -fold increase in IL-10, 3.4 \pm 0.6 -fold increase in MMR, $4.5 \pm 0.5$-fold increase in arginase, $2.6 \pm 0.2$-fold increase in

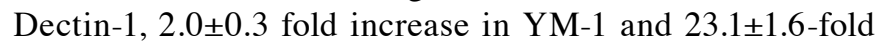
increase in YM-2 (Fig. 1A).

There was a small increase in pro-inflammatory gene expression when RAW264.7 cells were treated with $400 \mu \mathrm{g} / \mathrm{ml}$ APS (Fig. 1B). For example, APS increased iNOS expression by $1.7 \pm 0.8$-fold and TNF- $\alpha$ by $1.8 \pm 0.2$-fold. No statistically significant increase in IL-6, IL-1 $\beta$ and CD11c expression was achieved. There was also a small inhibition in MCP-1 mRNA expression. Additionally, APS inhibited palmitate-stimulated expression of most pro-inflammatory genes in RAW264.7 cells, including IL-1 $\beta$ by $57 \pm 4 \%$, iNOS by $48 \pm 2 \%$, MCP-1 by $73 \pm 3 \%$, CD11c by $32 \pm 5 \%$ and IL- 6 by $77 \pm 2 \%$ (Fig. 1B). Taken together, these results revealed that APS modulates the expression of most of the pro-inflammatory genes and induces the expression of anti-inflammatory genes in RAW264.7 cells following palmitate treatment.

APS enhances the expression of IL-10 protein and reduces $I L-1 \beta$ secretion in RAW264.7 cells. To evaluate the antiinflammatory effects of APS in RAW264.7 cells, IL-10 protein was analyzed following APS treatment for $24 \mathrm{~h}$. IL-10 protein gradually increased with escalating APS concentrations of 100, 200, 400 and $800 \mu \mathrm{g} / \mathrm{ml}$ (Fig. 2A). To further ascertain whether APS regulates protein secretion in the presence of palmitate, IL-10 and IL- $1 \beta$ protein was analyzed to evaluate the inflammatory effects of APS in RAW264.7 cells. RAW264.7 cells were pretreated with $400 \mu \mathrm{g} / \mathrm{ml}$ APS for $24 \mathrm{~h}$. APS enhanced IL-10 protein secretion $(3.9 \pm 0.4$ fold in the palmitate groups) and reduced IL- $1 \beta$ protein production (by $51.9 \pm 10 \%$ in the palmitate groups) in the palmitate-induced macrophage RAW264.7 cells (Fig. 2B and C). These results demonstrated that APS enhanced the expression of IL-10 
A

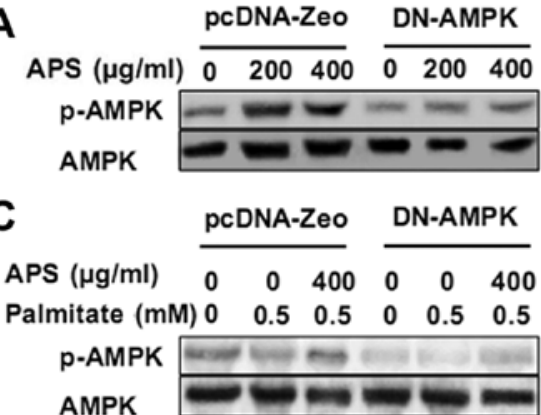
AMPK
B

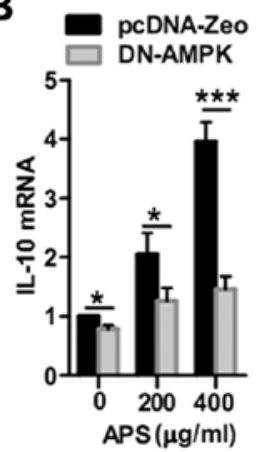

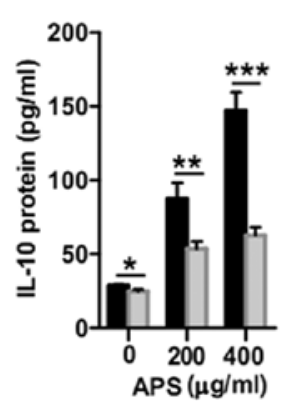
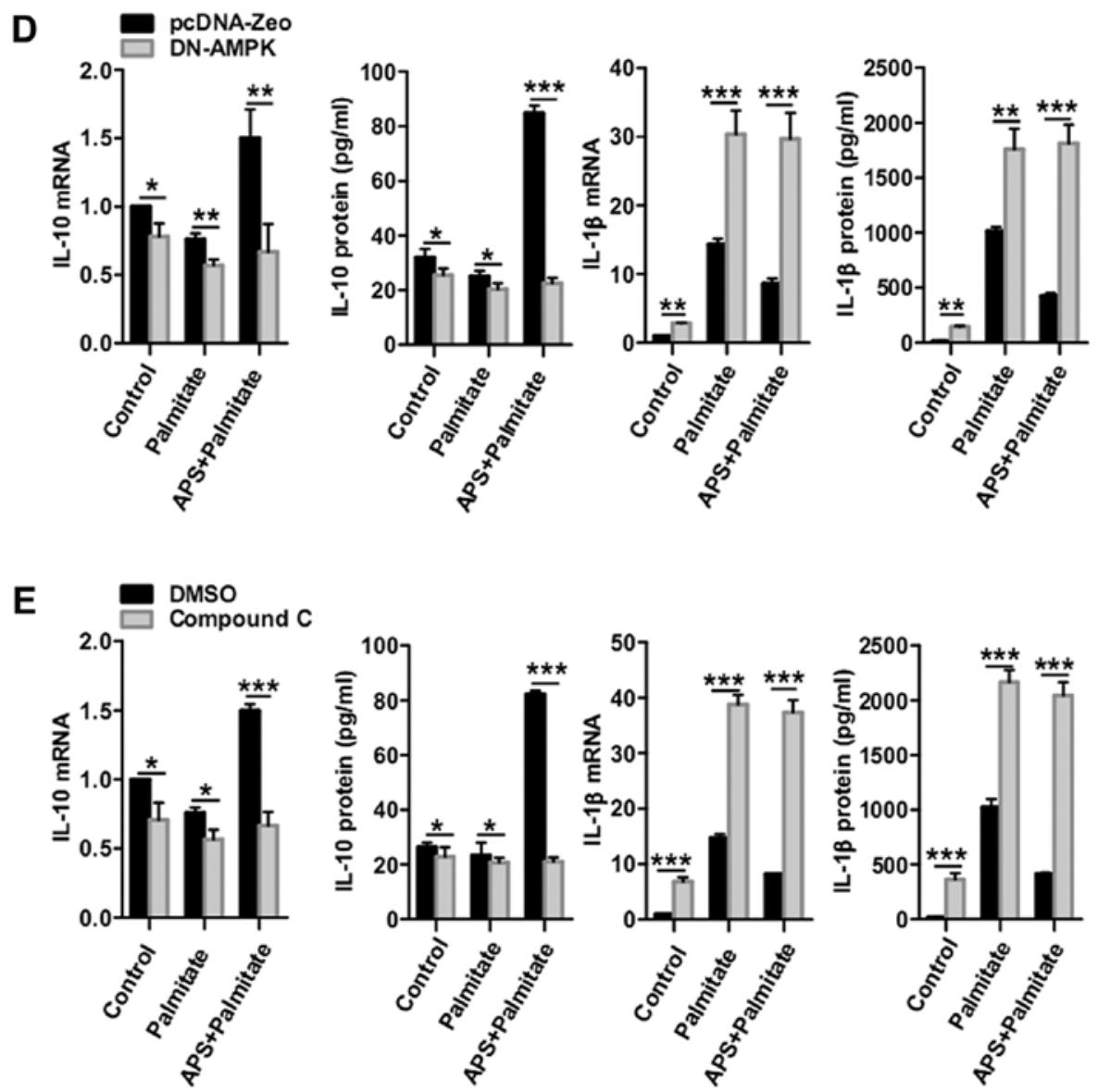

Figure 4. APS modulates IL-10 and IL-1 $\beta$ gene and protein expression, dependent on AMPK activity. (A) DN-AMPK $\alpha$ and pcDNA-Zeo groups were treated with or without APS for $3 \mathrm{~h}$. (B) IL-10 mRNA and protein levels in the DN-AMPK $\alpha$ and pcDNA-Zeo macrophages; the cells were treated with or without APS for $24 \mathrm{~h}$. (C) DN-AMPK $\alpha$ and pcDNA-Zeo macrophages were pretreated with $(400 \mu \mathrm{g} / \mathrm{ml})$ or without APS for $3 \mathrm{~h}$ and then cultured with palmitate for $2 \mathrm{~h}$. (D) IL-10 and IL-1 $\beta$ mRNA and protein levels in DN-AMPK $\alpha$ and pcDNA-Zeo macrophages; the cells were pretreated with (400 $\mu \mathrm{g} / \mathrm{ml})$ or without APS for $24 \mathrm{~h}$ and then cultured with palmitate for $12 \mathrm{~h}$. (E) IL-10 and IL-1 $\beta$ mRNA and protein levels in macrophages with or without compound C; the cells were treated with $400 \mu \mathrm{g} / \mathrm{ml}$ APS for $24 \mathrm{~h}$ after a treatment of compound $\mathrm{C}$ for $1 \mathrm{~h}$, and then cultured with palmitate for $12 \mathrm{~h}$. Data shown are the mean \pm SD of triplicate determinations and represent 3 independent experiments with similar results. ${ }^{*} \mathrm{P}<0.05,{ }^{* *} \mathrm{P}<0.01$ and ${ }^{* * * *} \mathrm{P}<0.001$ compared with the marked groups.

protein and suppressed IL-1 $\beta$ secretion in palmitate-treated RAW264.7 cells.

APS recovers the impaired AMPK activity induced by palmitate. APS rapidly stimulated AMPK activity in the RAW264.7 cells in a concentration-dependent manner after $15 \mathrm{~min}$ (Fig. 3A and B). APS recovered the impaired AMPK activity induced by palmitate $(1.8 \pm 0.2$-fold with $0.25 \mathrm{mM}$ palmitate, and $2.1 \pm 0.3$-fold with $0.5 \mathrm{mM}$ palmitate, respectively) (Fig. 3C).
APS modulates IL-10 and IL-1 $\beta$ gene and protein expression, dependent on AMPK activity. To further ascertain whether APS-regulated IL-10 and IL-1 $\beta$ expression is dependent on AMPK activity, RAW264.7 cells were transfected with DN-AMPK $\alpha$ to inhibit AMPK activity (Fig. 4A and C). Compared with the pcDNA-Zeo control group, DN-AMPK groups treated for $24 \mathrm{~h}$ with 200 and $400 \mu \mathrm{g} / \mathrm{ml}$ of APS showed significant decreases in IL- 10 mRNA by $39 \pm 10$ and $63 \pm 6 \%$, respectively. IL-10 protein secretion in the DN-AMPK groups was abrogated by $39 \pm 5 \%$ with $200 \mu \mathrm{g} / \mathrm{ml}$ APS treatment 
A

mpcDNA-Zeo

DN-AMPK
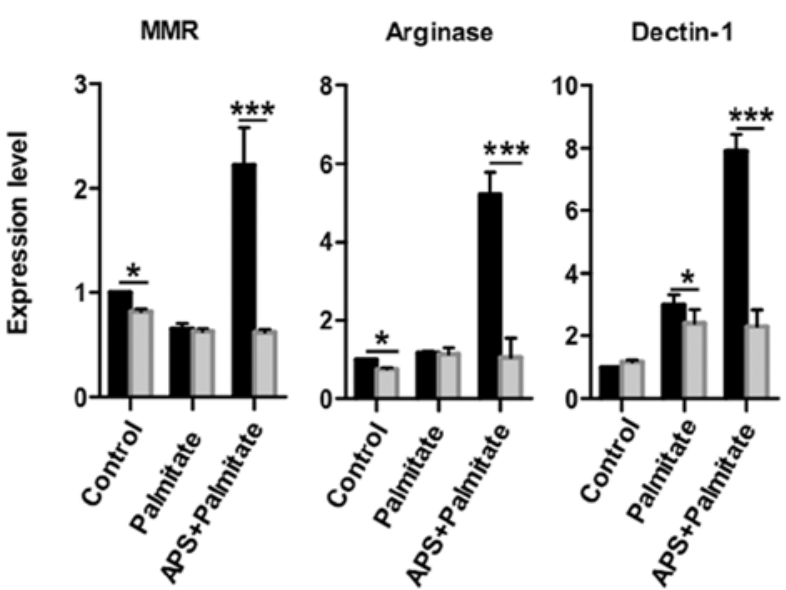

YM-1

YM-2

B

pcDNA-Zeo

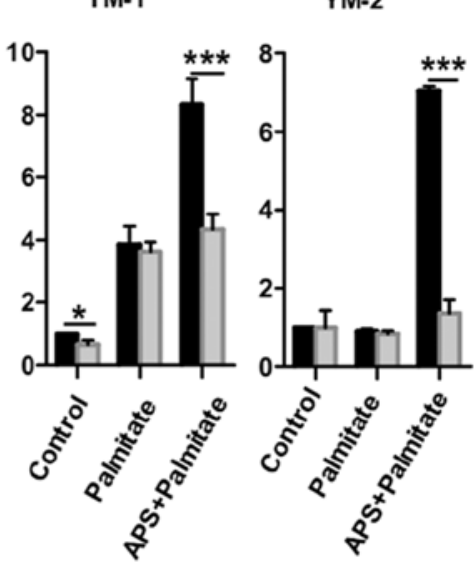

DN-AMPK
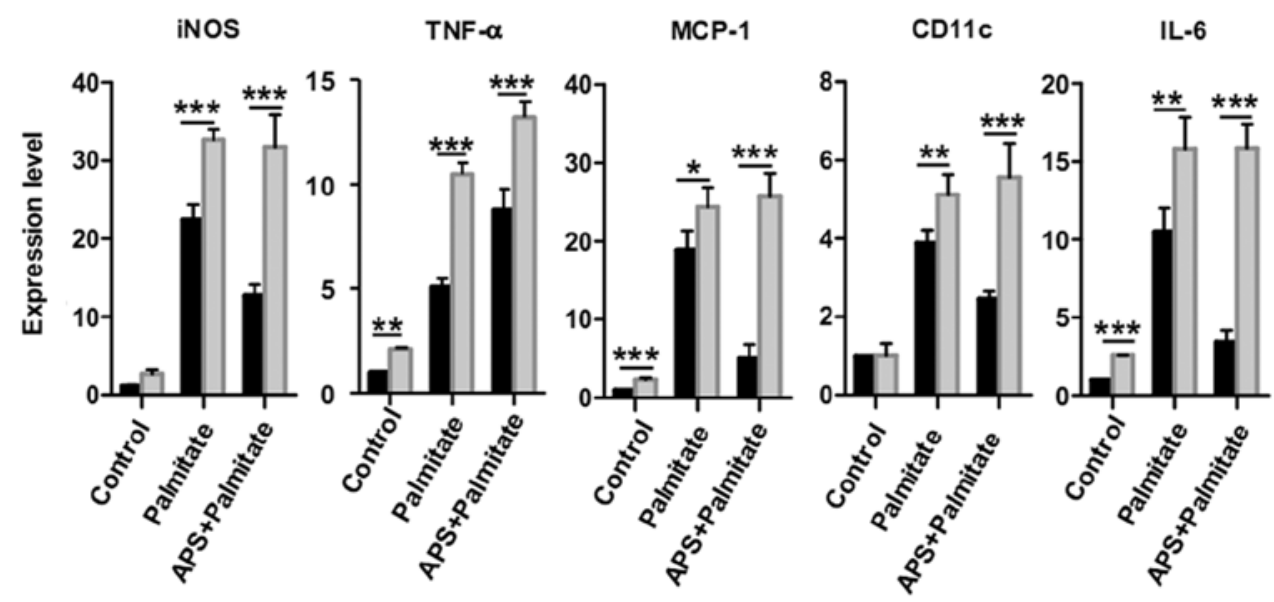

Figure 5. APS modulates the expression of inflammatory genes, dependent on AMPK activity. RAW264.7 cells transfected with DN-AMPK and pcDNA-Zeo were pretreated with $(400 \mu \mathrm{g} / \mathrm{ml})$ or without APS for $24 \mathrm{~h}$, and were then cultured with palmitate $(0.5 \mathrm{mM})$ for $12 \mathrm{~h}$. The groups without APS or palmitate were designated as the control. (A) MMR, arginase, Dectin-1, YM-1 and YM-2 were analyzed as anti-inflammatory genes. (B) iNOS, TNF- $\alpha$, MCP-1, CD11c and IL-6 were analyzed as pro-inflammatory genes. Data shown are the means \pm SD of triplicate determinations and represent 3 independent experiments with similar results. ${ }^{*} \mathrm{P}<0.05,{ }^{* *} \mathrm{P}<0.01$ and ${ }^{* * *} \mathrm{P}<0.001$ compared with the marked groups.

and by $57 \pm 3 \%$ with $400 \mu \mathrm{g} / \mathrm{ml}$ APS treatment (Fig. 4B). Furthermore, DN-AMPK macrophages were pretreated with $400 \mu \mathrm{g} / \mathrm{ml}$ APS for $24 \mathrm{~h}$ and treated again with palmitate for $12 \mathrm{~h}$. APS-dependent recovery of IL-10 mRNA in the presence of palmitate $(0.5 \mathrm{mM})$ was inhibited by AMPK impairment by $55 \pm 13 \%$. AMPK impairment also inhibited the recovery of IL-10 protein production by $73 \pm 2 \%$ (Fig. 4D). Meanwhile, APS-dependent inhibition of IL-1 $\beta$ mRNA and protein in the presence of palmitate $(0.5 \mathrm{mM})$ was abrogated by AMPK impairment (Fig. 4D). Consistently, compound C, an AMPK inhibitor, also abrogated the APS-dependent IL-10 recovery and IL-1 $\beta$ inhibition in the presence of palmitate $(0.5 \mathrm{mM})$ (Fig. 4E). These results demonstrate that the enhancement of IL-10 and suppression of IL-1 $\beta$ in RAW264.7 cells following palmitate treatment was caused by APS and was dependent on AMPK activity.

APS modulates the expression of inflammatory genes in a manner dependent on AMPK activity. To further identify whether APS modulates the expression of inflammatory genes through AMPK activity, DN-AMPK and pcDNA-Zeo plasmids were transfected into RAW264.7 cells to inhibit AMPK activity, respectively (13). When comparing the DN-AMPK and pcDNA-Zeo groups, the APS-dependent recovery of anti-inflammatory genes in the present of palmitate $(0.5 \mathrm{mM})$ had a decrease of $72 \pm 1 \%$ for MMR, $80 \pm 9 \%$ for arginase, $71 \pm 7 \%$ for Dectin-1, 48 $\pm 6 \%$ for YM-1 and $81 \pm 5 \%$ for YM-2 (Fig. 5A). Conversely, when comparing the DN-AMPK and pcDNA-Zeo groups, APS-dependent suppression of pro-inflammatory genes in the present of palmitate $(0.5 \mathrm{mM})$ showed an increase of 1.5 \pm 0.3 -fold for iNOS, 4.0 \pm 0.6 -fold for MCP-1, 1.3 \pm 0.6 -fold for CD11c and 3.6 \pm 0.4 -fold for IL-6 (Fig. 5B). Unexpectedly, AMPK impairment also increased the expression of TNF- $\alpha$ mRNA in the palmitate or APS-pretreated groups, but this increase did not depend on AMPK activity. These results imply that the loss of AMPK activity inhibits the expression of most anti-inflammatory genes and abrogates APS-induced inhibition of pro-inflammatory genes except for TNF- $\alpha$. 


\section{Discussion}

Many studies have established the relationship between chronic low-grade inflammation and metabolic disorders such as insulin resistance and diabetes mellitus $(1,2)$. Inflammatory cells and inflammation are key players in obesity and insulin resistance $(2,4,21)$. APS has hypoglycemic activity and increases insulin sensitivity $(8,9,12,18)$. Recent studies have demonstrated that APS ameliorates diabetes and may have anti-inflammatory effects $(10,11)$. However, the effect of APS on inflammatory cells is still uncertain. RAW264.7 is a murine macrophage cell line that is widely used to study inflammatory responses associated with metabolic disorders (4-6). Palmitate is one of the main culprits involved in macrophage inflammatory responses in metabolic disorders $(4,5)$. Here, we demonstrated that APS evokes anti-inflammatory responses in murine macrophage RAW264.7 cells with or without palmitate treatment. This suggests that APS plays an essential role in regulating inflammatory responses. Thus, APS may potentially be used for the prevention and treatment of metabolic disorders.

Recent research has demonstrated that APS increases proinflammatory cytokine expression levels, including TNF- $\alpha$ and NO production, in RAW264.7 cells $(16,17)$. However, this observation conflicts with the roles of APS in improving insulin resistance and hypoglycemic activity $(8,9,12,18)$. In the present study, we evaluated the expression of several important anti-inflammatory and pro-inflammatory genes activated by APS to establish this regulation in RAW264.7 cells. As a whole, APS exhibited anti-inflammatory effects. Firstly, an important anti-inflammatory gene, IL-10, was analyzed and increased gene levels were found. Furthermore, expression of anti-inflammatory genes, MMR, arginase, Dectin-1, YM-1 and YM-2, increased after APS treatment in RAW264.7 cells (Fig. 1A). However, only two genes, iNOS and TNF- $\alpha$, showed increased expression among the pro-inflammatory genes. Other pro-inflammatory genes, including IL-6, IL-1 $\beta$ and CD11c, had no statistically significant change and MCP-1 exhibited a slight inhibition (Fig. 1B). IL-10 protein expression increased gradually with escalating APS concentrations (Fig. 2A). APS enhanced IL-10 protein production but IL-1 $\beta$ protein secretion had no statistically significant change after APS treatment in RAW264.7 cells (Fig. 2B and C). IL-10 plays important beneficial roles in improving metabolic disorders (22), while IL-1 $\beta$ plays important roles in accelerating metabolic disorders $(23,24)$. Our results better explain the roles of APS in metabolic disorders $(8,9,12,18)$ and these results also showed that APS stimulated the expression of most anti-inflammatory genes and only two pro-inflammatory genes. Therefore, we demonstrated that APS stimulates RAW264.7 cells to an antiinflammatory polarization $(20,21)$.

AMPK was demonstrated to be a good cellular regulator for insulin resistance and diabetes in metabolic disorders (25). Recent evidence revealed that AMPK is also involved in regulating inflammatory responses $(6,13,26)$. We found that APS stimulates RAW264.7 cells to an anti-inflammatory polarization. However, whether APS stimulates AMPK activity in RAW264.7 cells is still unknown. Phosphorylation of the $\alpha$ subunit at the site of Thr172 residue is crucial for AMPK activity (25). In the present study, RAW264.7 cells were treated with APS for the indicated time periods or treated with various APS concentrations for the same time. Results showed that APS rapidly increased phosphorylation of AMPK (Thr172) in a dose-dependent manner (Fig. 3A and B). Furthermore, APS recovered the impaired AMPK phosphorylation induced by palmitate (Fig. 3C). Therefore, we demonstrated that APS stimulates AMPK activity in RAW264.7 cells with or without palmitate treatment.

APS has shown anti-inflammatory effects on LPS-induced inflammation in several cell lines $(14,15)$. One published study demonstrated that the characterization of inflammation induced by LPS was different from that induced by palmitate (4). However, whether APS has anti-inflammatory effects on palmitate-induced inflammation is still unknown. In this study, we provide a model for APS regulation of inflammation in metabolic disorders by showing that APS enhanced antiinflammatory gene expression in palmitate-treated groups (Fig. 1A). Meanwhile, APS decreased the expression of most of the palmitate-induced pro-inflammatory genes, except for TNF- $\alpha$ (Fig. 1B). Additionally, APS reduced IL-1 $\beta$ protein and recovery of IL-10 protein production caused by palmitate in RAW264.7 cells (Fig. 2B and C). These results demonstrated that APS plays anti-inflammatory roles in RAW264.7 cells following palmitate treatment.

Although studies have found that APS has an antiinflammatory effect, involvement of AMPK activity has not been demonstrated to be correlated with the roles of APS $(14,15,27,28)$. In the present study, to identify whether the anti-inflammatory effects of APS in RAW264.7 cells following the treatment of palmitate are associated with AMPK activity, inhibitors of AMPK, such as the DN-AMPK plasmid or compound $\mathrm{C}$, were used to investigate the anti-inflammatory effect of APS while AMPK activity was blocked. Inhibition of AMPK activity abrogated these effects besides expression of anti-inflammatory genes, including IL-10, MMR, arginase, Dectin-1, YM-1 and YM-2 (Figs. 4 and 5A). Additionally, APS decreased the expression of most of the palmitate-induced pro-inflammatory genes, except for TNF- $\alpha$ (Fig. 1B). These effects were abrogated by the loss of AMPK activity (Fig. 5B). Moreover, other unknown mechanisms may be involved in the promotion of TNF- $\alpha$ expression in APS-treated RAW264.7 cells in the presence of palmitate, independent of AMPK activity. Thus, APS recovers the expression of most of the anti-inflammatory genes and inhibits the expression of several pro-inflammatory genes in the presence of palmitate, in a manner dependent on AMPK activity.

In summary, we demonstrated that APS stimulates RAW264.7 cells to an anti-inflammatory polarity and has antiinflammatory effects in palmitate-induced RAW264.7 cells. These anti-inflammatory effects are dependent on AMPK activity. Thus, APS can potentially be a useful therapeutic candidate for the prevention and treatment of inflammatory disorders.

\section{Acknowledgements}

This study was supported by grants from the National Basic Research Program of China (2010CB529800), the National Science and Technology Major Projects of New Drugs (2012ZX09103301-028), the National Natural Sciences 
Foundation of China to H.X.H. and H.S. (nos. 81171127 and 31000344), and the Natural Science Foundation of Hubei Province of China (2010CDA045).

\section{References}

1. Greenfield JR and Campbell LV: Relationship between inflammation, insulin resistance and type 2 diabetes: 'cause or effect'? Curr Diabetes Rev 2: 195-211, 2006.

2. Permana PA, Menge $C$ and Reaven PD: Macrophage-secreted factors induce adipocyte inflammation and insulin resistance. Biochem Biophys Res Commun 341: 507-514, 2006.

3. Bray GA, Lovejoy JC and Smith SR, et al: The influence of different fats and fatty acids on obesity, insulin resistance and inflammation. J Nutr 132: 2488-2491, 2002.

4. Samokhvalov V, Bilan PJ, Schertzer JD, Antonescu CN and Klip A: Palmitate- and lipopolysaccharide-activated macrophages evoke contrasting insulin responses in muscle cells. Am J Physiol Endocrinol Metab 296: E37-E46, 2009.

5. Nguyen MT, Favelyukis S and Nguyen AK, et al: A subpopulation of macrophages infiltrates hypertrophic adipose tissue and is activated by free fatty acids via Toll-like receptors 2 and 4 and JNK-dependent pathways. J Biol Chem 282: 35279-35292, 2007.

6. Jeong HW, Hsu KC and Lee JW, et al: Berberine suppresses proinflammatory responses through AMPK activation in macrophages. Am J Physiol Endocrinol Metab 296: E955-E964, 2009.

7. Denzler KL, Waters R, Jacobs BL, Rochon Y and Langland JO Regulation of inflammatory gene expression in PBMCs by immunostimulatory botanicals. PLoS One 5: e12561, 2010.

8. Chen W, Xia YP, Chen WJ, Yu MH, Li YM and Ye HY: Improvement of myocardial glycolipid metabolic disorder in diabetic hamster with Astragalus polysaccharide treatment. Mol Biol Rep 39: 7609-7615, 2012.

9. Liu M, Wu K, Mao X, Wu Y and Ouyang J: Astragalus polysaccharide improves insulin sensitivity in KKAy mice: regulation of PKB/GLUT4 signaling in skeletal muscle. J Ethnopharmacol 127: 32-37, 2010

10. Chen W, Li Y and Yu M: Astragalus polysaccharides: an effective treatment for diabetes prevention in NOD mice. Exp Clin Endocrinol Diabetes 116: 468-474, 2008.

11. Li RJ, Qiu SD, Chen HX, Tian H and Wang HX: The immunotherapeutic effects of Astragalus polysaccharide in type 1 diabetic mice. Biol Pharm Bull 30: 470-476, 2007.

12. Zou F, Mao XQ, Wang N, Liu J and Ou-Yang JP: Astragalus polysaccharides alleviate glucose toxicity and restores glucose homeostasis in diabetic states via activation of AMPK. Acta Pharmacol Sin 30: 1607-1615, 2009.

13. Sag D, Carling D, Stout RD and Suttles J: Adenosine 5'-monophosphate-activated protein kinase promotes macrophage polarization to an anti-inflammatory functional phenotype. $\mathrm{J}$ Immunol 181: 8633-8641, 2008.
14. Shon YH, Kim JH and Nam KS: Effect of Astragali radix extract on lipopolysaccharide-induced inflammation in human amnion. Biol Pharm Bull 25: 77-80, 2002.

15. He X, Shu J, Xu L, Lu C and Lu A: Inhibitory Effect of Astragalus polysaccharides on lipopolysaccharide-induced TNF- $\alpha$ and IL-1 $\beta$ production in THP-1 cells. Molecules 17: 3155-3164, 2012.

16. Zhao LH, Ma ZX, Zhu J, Yu XH and Weng DP: Characterization of polysaccharide from Astragalus radix as the macrophage stimulator. Cell Immunol 271: 329-334, 2011.

17. Lee KY and Jeon YJ: Macrophage activation by polysaccharide isolated from Astragalus membranaceus. Int Immunopharmacol 5: 1225-1233, 2005.

18. Wang N, Zhang D, Mao X, Zou F, Jin H and Ouyang J: Astragalus polysaccharides decreased the expression of PTP1B through relieving ER stress induced activation of ATF6 in a rat model of type 2 diabetes. Mol Cell Endocrinol 307: 89-98, 2009.

19. Schmitz-Peiffer C, Craig DL and Biden TJ: Ceramide generation is sufficient to account for the inhibition of the insulin-stimulated PKB pathway in C2C12 skeletal muscle cells pretreated with palmitate. J Biol Chem 274: 24202-24210, 1999.

20. Lefevre L, Gales A, Olagnier D, et al: PPARgamma ligands switched high fat diet-induced macrophage M2b polarization toward M2a thereby improving intestinal Candida elimination. PLoS One 5: e12828, 2010.

21. Oh DY, Talukdar S, Bae EJ, et al: GPR120 is an omega-3 fatty acid receptor mediating potent anti-inflammatory and insulinsensitizing effects. Cell 142: 687-698, 2010.

22. Hong EG, Ko HJ, Cho YR, et al: Interleukin-10 prevents dietinduced insulin resistance by attenuating macrophage and cytokine response in skeletal muscle. Diabetes 58: 2525-2535, 2009.

23. Gabay C, Lamacchia C and Palmer G: IL-1 pathways in inflammation and human diseases. Nat Rev Rheumatol 6: 232-241, 2010.

24. Speaker KJ and Fleshner M: Interleukin-1 beta: a potential link between stress and the development of visceral obesity. BMC Physiol 12: 8, 2012.

25. Schimmack G, Defronzo RA and Musi N: AMP-activated protein kinase: role in metabolism and therapeutic implications. Diabetes Obes Metab 8: 591-602, 2006.

26. Hattori Y, Suzuki K, Hattori S and Kasai K: Metformin inhibits cytokine-induced nuclear factor kappaB activation via AMP-activated protein kinase activation in vascular endothelial cells. Hypertension 47: 1183-1188, 2006.

27. Yuan Y, Sun M and Li KS: Astragalus mongholicus polysaccharide inhibits lipopolysaccharide-induced production of TNF-alpha and interleukin-8. World J Gastroenterol 15: 3676-3680, 2009.

28. Jiang JB, Qiu JD, Yang LH, He JP, Smith GW and Li HQ: Therapeutic effects of astragalus polysaccharides on inflammation and synovial apoptosis in rats with adjuvant-induced arthritis. Int J Rheum Dis 13: 396-405, 2010. 